\title{
Appropriateness of Therapeutic Antibiotic Prescriptions by Lebanese Dentists in the Management of Acute Endodontic Abscesses
}

\author{
Ghada Al Asmar Ramli ${ }^{1}$, Jacques E. Mokhbat ${ }^{2}$, Dominique Cochelard ${ }^{3}$, Mohamed Lemdani ${ }^{4}$, Ahmed \\ Haddadi $^{5}$, Fouad Ayoub ${ }^{6}$ \\ 1. Orthodontics, Faculty of Dental Medicine, Lebanese University, Beirut, LBN 2. Infectious Disease, School of \\ Medicine, Lebanese American University, Beirut, LBN 3. Epidemiology and Public Health, Laboratoire \\ Biomathematiques, Lille 2 University, Lille, FRA 4. Epidemiology and Public Health, Laboratoire Biomathematiques, \\ Lille University, Lille, FRA 5. Public Health: Epidemiology and Quality of Care, Lille 2 University, Lille, FRA 6. Forensic \\ Odontology and Human Identification, Faculty of Dental Medicine, Lebanese University, Beirut, LBN
}

Corresponding author: Ghada Al Asmar Ramli, ghadaasmar@gmail.com

\begin{abstract}
The misuse of antibiotics in dentistry is a serious concern especially in regards to the emergence of antibiotic resistance. The objective of the study was to evaluate the appropriateness of antibiotics prescriptions by Lebanese dentists to patients with endodontic abscesses and their compliance with the guidelines of the American Association of Endodontists (AAE) and the European Society of Endodontology (ESE). The treating dentists recorded clinical information from 127 patients diagnosed with acute or chronic endodontic abscess. The information also included the type of antibiotic prescribed, dosage, and duration of the prescription. Prescriptions were not given to 14/20 patients with an acute endodontic abscess despite the presence of an indication to prescribe. All the prescriptions given to patients with an acute endodontic abscess were inappropriate according to the ESE and AAE guidelines. Antibiotics were also prescribed unnecessarily to $17 / 42$ patients with a chronic endodontic abscess. This study concluded that antibiotics prescriptions by Lebanese dentists for the management of endodontic abscesses were inappropriate. Penicillin V potassium (VK) was not available in Lebanon when the study was conducted. Only broadspectrum antibiotics were prescribed. This finding raises concerns about the emergence of antibiotic resistance.
\end{abstract}

Categories: Dentistry

Keywords: endodontics, dentistry, antibacterial agents, drug resistance

Received 03/06/2020

Review began 03/12/2020 Review ended 03/16/2020 Published 03/19/2020

\section{() Copyright 2020}

Al Asmar Ramli et al. This is an open access article distributed under the terms of the Creative Commons Attribution License CC-BY 4.0., which permits unrestricted use, distribution, and reproduction in any medium, provided the original author and source are credited.

\section{Introduction}

Most endodontic infections can be managed by drainage, endodontic treatment, or extraction [1-2]. However, in specific situations, these local measures may not be adequate and the prescription of antibiotics may be recommended [3-5]. The European Society of Endodontology (ESE) and the American Association of Endodontists (AAE) proposed guidelines regarding the indications to prescribe antibiotics, the type of antibiotic, and the prescription regimen in the presence of oro-facial infections of endodontic origin as a therapeutic measure [3-4].

Several studies have demonstrated that dentists from different jurisdictions do not comply with the recommended guidelines [6-13]. The non-compliance included the indication to prescribe, the type of antibiotic, and the regimen of the prescription. Moreover, several articles have raised concerns about the relationship between the inappropriate use of antibiotics and the emergence of antibiotic resistance [14-16].

There are no national guidelines in Lebanon for the therapeutic prescription of antibiotics in dentistry. One study suggested that Lebanese dentists did not follow international guidelines [17]. More recently, another study raised a similar concern despite the fact that Lebanese dentists were, in general, aware of the relationship between the emergence of bacterial resistance and antibiotic misuse [18].

The objective of the present study was to evaluate the compliance of Lebanese dentists with the AAE and ESE guidelines for the prescription of therapeutic antibiotics for dental infections of endodontic origin.

\section{Materials And Methods}

This study was approved by the Committee of Ethics, Faculty of Dentistry, Lebanese University, and was conducted over nine months. It involved patients from the dental clinics at the Faculty of Dentistry, Lebanese University, and 24 private dental clinics located in Beirut and its outskirts. Eligible patients met the following criteria: men or women aged 16 and above, clinically diagnosed with an acute endodontic abscess (AEA) or a chronic endodontic abscess (CEA) [19]. Patients who needed hospitalization were not included in the study. All dentists involved with these clinics followed a refresher course on the diagnosis of 


\section{Cureus}

endodontic disease with emphasis on acute and chronic endodontic abscesses.

The dentists were asked to record the information presented in Table 1 when a patient presented with an AEA or a CEA.

Diagnosis of acute or chronic apical abscess

Fatigue

Fever

Trismus

Lymphadenopathy

Difficulty in swallowing

Blurry vision

Medically compromised patient

Progressive infection (rapid onset $24 \mathrm{~h}$, progressive swelling, osteomyelitis, cellulitis)

Persisting infection

Extraction

Incision and drainage, intracanal drainage

Endodontic treatment

Antibiotic prescription (type, dosage/loading dose, duration)

TABLE 1: Clinical parameters collected for each patient

At the end of the study period, information was collected. The information for each patient to whom antibiotics were prescribed was assessed for compliance with the ESE and AAE guidelines with regards to the indication to prescribe antibiotics and the antibiotic prescription (type, dosage, and duration).

\section{Results}

One-hundred twenty-seven patients were diagnosed with either an acute $(n=85)$ or a chronic $(n=42)$ endodontic abscess. The information collected from the different clinics was complete for all the patients.

Seventeen patients with a chronic endodontic abscess were prescribed therapeutic antibiotics unnecessarily and contrary to the ESE and AAE guidelines.

Antibiotics were not prescribed to 20/85 patients with an AEA. The remaining 65/85 patients received a prescription. The antibiotics were inappropriately prescribed to 62/65 patients with an AEA according to the ESE and AAE guidelines. The inappropriateness involved the indication to prescribe, the prescribed antibiotic, the dosage, and the duration of the prescription. Prescriptions non-compliant with the ESE guidelines alone were given to $3 / 65$ patients (Table 2). None of the prescriptions was non-compliant with the AAE guidelines alone. 


\section{Cureus}

\begin{tabular}{|c|c|c|c|c|}
\hline $\begin{array}{l}\text { Total number of } \\
\text { patients with } \\
\text { AEA }^{\star} \text { and with a } \\
\text { prescription }\end{array}$ & $\begin{array}{l}\text { Total number of patients with } \\
\mathrm{AEA}^{*} \text { and with a prescription, } \\
\text { and without compliance with } \\
\mathrm{ESE}^{\star \star} \text { or } \mathrm{AAE}^{+}\end{array}$ & $\begin{array}{l}\text { Total number of patients with } \\
\mathrm{AEA}^{*} \text { and with a prescription, } \\
\text { and without compliance with } \\
\mathrm{ESE}^{\star \star} \text { and } \mathrm{AAE}^{+}\end{array}$ & $\begin{array}{l}\text { Total number of patients } \\
\text { with AEA* and with a } \\
\text { prescription, and without } \\
\text { compliance with ESE }{ }^{\star *}\end{array}$ & $\begin{array}{l}\text { Total number of patients } \\
\text { with } \mathrm{AEA}^{*} \text { and with a } \\
\text { prescription, and without } \\
\text { compliance with } \mathrm{AAE}^{+}\end{array}$ \\
\hline 65 & 65 & 62 & 3 & 0 \\
\hline
\end{tabular}

TABLE 2: Patients with AEA and with an antibiotic prescription: non-compliance with ESE and AAE guidelines.

*AEA: Acute endodontic abscess; ${ }^{\star \star}$ ESE: European Society of Endodontology; ${ }^{+}$AAE: American Association of Endodontics

Antibiotics were not prescribed to 20/85 patients with an AEA. Six of these patients $(6 / 20)$ were appropriately managed according to the AAE and ESE recommendations: those patients did not need a prescription. Fourteen patients (14/20) were not well managed according to the ESE/AAE guidelines: they were not given a prescription despite the presence of an indication to prescribe. For 6/14 patients, the absence of the prescription was not compliant with the ESE and AAE guidelines; i.e., a prescription should have been given to these patients. Non-compliance with the ESE guidelines alone involved an additional eight patients (Table 3).

\begin{tabular}{|c|c|c|c|c|}
\hline $\begin{array}{l}\text { Total number of } \\
\text { patients with } \\
\mathrm{AEA}^{\star} \text { and } \\
\text { without a } \\
\text { prescription }\end{array}$ & $\begin{array}{l}\text { Total number of patients with } \\
\mathrm{AEA}^{\star} \text { and without a } \\
\text { prescription, and without } \\
\text { compliance with } \mathrm{ESE}^{\star \star} \text { or } \\
\mathrm{AAE}^{+}\end{array}$ & $\begin{array}{l}\text { Total number of patients with } \\
\mathrm{AEA}^{\star} \text { and without a } \\
\text { prescription, and without } \\
\text { compliance with } \mathrm{ESE}^{\star \star} \text { and } \\
\mathrm{AAE}^{+}\end{array}$ & $\begin{array}{l}\text { Total number of patients } \\
\text { with } \text { AEA* and without a }^{*} \\
\text { prescription, and without } \\
\text { compliance with ESE** }\end{array}$ & $\begin{array}{l}\text { Total number of patients } \\
\text { with } \mathrm{AEA}^{\star} \text { and without a } \\
\text { prescription, and without } \\
\text { compliance with } \mathrm{AAE}^{+}\end{array}$ \\
\hline 20 & 14 & 6 & 14 & 6 \\
\hline
\end{tabular}

TABLE 3: Patients with AEA and without an antibiotic prescription: non-compliance related to indication.

*AEA: Acute endodontic abscess; ${ }^{*}$ ESE: European Society of Endodontology; +AAE: American Association of Endodontics

\section{Discussion}

The clinical situations presented in Table 1 were used by the ESE and AAE to determine the need to prescribe antibiotics [3-4]. They were included in the information collection in the present study because they allow the determination of the degree of compliance with ESE and AAE guidelines.

To the knowledge of the authors, this was the first prospective observational study to evaluate the prescribing patterns of antibiotics by Lebanese dentists in the presence of an endodontic abscess and the compliance of the prescriptions with the ESE and AAE guidelines.

During a period of nine months, a total of 127 patients presented with apical disease, chronic (42 patients) or acute (85 patients). Prescriptions were given to 85 patients (63.78\%); 65 and 20 patients with an AEA or CEA, respectively. Antibiotics were not given to 20 and 25 patients with an AEA or CEA, respectively.

Non-compliance of prescriptions with the ESE and AAE guidelines occurred with 65 patients with an acute endodontic abscess and was related to the indication to prescribe $(n=46)$ and the adequacy of the prescription, including antibiotic molecule, dosage, and duration $(\mathrm{n}=51)$. It was noteworthy that Penicillin VK, a narrow-spectrum antibiotic, was not prescribed to any patient. Penicillin VK was recommended by the AAE and ESE as the antibiotic of choice for the management of endodontic infections [3-4]. It appeared that this antibiotic was not available in Lebanon at the time of the study. Dentists instead prescribed a broadspectrum antibiotic for every patient included in the present study. This finding raised serious concerns about the emergence of resistant bacteria strains associated with the use of broad-spectrum molecules [2021]. The World Health Organization stressed that antimicrobial resistance to antibiotics is a global health concern [22]. The other elements of non-compliance such as the indication to prescribe and the duration and dosage of the prescription would also be implicated in the emergence of antibiotic resistance [21]. 
patients, the prescriptions were not compliant with the ESE recommendations. An additional three patients were given prescriptions non-compliant only with the ESE guidelines. Those three patients were medically compromised and presented with a diffuse swelling, which was an indication to prescribe according to the ESE guidelines. However, the patients were prescribed amoxicillin instead of penicillin VK as recommended by the ESE. The prescriptions for these patients were compliant with the AAE guidelines according to which similar patients should receive amoxicillin. Therefore, the difference between the number of prescriptions non-compliant $(n=3)$ with the ESE $(n=65)$ and the AAE $(n=62)$ was related to differences in the guidelines involving the prescription $(n=3)$.

Non-compliance did not only involve prescriptions given to patients presenting with an acute endodontic abscess. Non-compliance was also found with eight patients who were not prescribed antibiotics despite the presence of an indication to prescribe. Five patients would receive an antibiotic prescription if the AAE guidelines were followed. The same five patients would be given a prescription according to the ESE guidelines. An additional three patients should have received a prescription following the ESE recommendations. The difference between the number of patients who were mismanaged by not prescribing antibiotics $(n=3)$ according to the ESE $(n=8)$ and the AAE $(n=5)$ confirmed the presence of differences between the ESE and the AAE with regards to the indication to prescribe antibiotics to patients with an AEA. All of these three patients were medically compromised and presented with localized edema, which is an indication to prescribe antibiotics, in addition to performing a root canal treatment according to the ESE but not the AAE, which recommends the initiation of a root canal procedure to control the infection in the presence of localized edema, instead of prescribing antibiotics [4].

It was also noteworthy that dentists prescribed antibiotics unnecessarily, and contrary to the ESE and AAE guidelines, to $17 / 42$ patients presenting with a CEA. It has been well-established that therapeutic antibiotics should not be given in these situations [3-4]. Considering that all the 17 prescriptions, to patients who will not benefit from them, consisted of a broad-spectrum antibiotic, this finding raised the authors' concerns regarding the occurrence of pseudomembranous colitis and antibiotic resistance, which are more likely to develop with this type of antibiotic [20-21,23].

\section{Conclusions}

In agreement with other studies, the present study demonstrated that dentists, in general, prescribed antibiotics inappropriately in the presence of dental infection. More specifically, this study confirmed the impression that Lebanese dentists have poor antibiotics-prescribing patterns in the presence of dental infection. The findings were an indication of the lack of knowledge of the dentists. This aspect should be investigated especially with regards to the curriculum taught in dental schools in Lebanon. At a national level, the unavailability of narrow-spectrum antibiotics in Lebanon should be alarming.

\section{Additional Information \\ Disclosures}

Human subjects: Consent was obtained by all participants in this study. CUEMB-Lebanese University issued approval 13. The institutional review board and ethical committee of the Lebanese University approved this clinical study on Lebanese patients. Animal subjects: All authors have confirmed that this study did not involve animal subjects or tissue. Conflicts of interest: In compliance with the ICMJE uniform disclosure form, all authors declare the following: Payment/services info: All authors have declared that no financial support was received from any organization for the submitted work. Financial relationships: All authors have declared that they have no financial relationships at present or within the previous three years with any organizations that might have an interest in the submitted work. Other relationships: All authors have declared that there are no other relationships or activities that could appear to have influenced the submitted work.

\section{References}

1. American Association of Endodontists. Antibiotics and the treatment of endodontic infections . (2006). Accessed: February 22, 2020: https://www.aae.org/specialty/wpcontent/uploads/sites/2/2017/07/summer06ecfe.pdf.

2. European Society of Endodontology: Quality guidelines for endodontic treatment: consensus report of the European Society of Endodontology. Int Endod J. 2006, 39:921-930. 10.1111/j.1365-2591.2006.01180.x

3. Segura-Egea J, Gould K, Hakan S, et al.: European Society of Endodontology position statement: the use of antibiotics in endodontics. Int Endod J. 2018, 51:20-25. 10.1111/iej.12781

4. American Association of Endodontists. Use and abuse of antibiotics . (2012). Accessed: February 22, 2020: https://www.aae.org/specialty/wp-content/uploads/sites/2/2017/07/ecfewinter12final.pdf.

5. ADA Council on Scientific Affairs: Antibiotic use in dentistry. J Am Dent Assoc. 1997, 128:648.

6. Brinkman J, Nijland N, Van Diermen E, et al.: Are Dutch dental students and dental-care providers competent prescribers of drugs?. Eur J Oral Sci. 2019, 127:531-538. 10.1111/eos.12658

7. Halboub E, Alzaili A, Quadri MF, Al-Haroni M, Al-Obaida MI, Al-Hebshi NN: Antibiotic prescription knowledge of dentists in Kingdom of Saudi Arabia: an online, country-wide survey. J Contemp Dent Pract. 2016, 17:198-204. 10.5005/jp-journals-10024-1827

8. Gaballah K, Adel A, Bahmani A, Salami A, Hassan N: The knowledge and attitude of practicing dentists 
towards the antibiotic prescription: a regional Study. Br J Pharm Res. 2014, 4:2006-2018. 10.9734/BJPR/2014/12520

9. FGDP. Adult antimicrobial prescribing in primary dental care for general dental practitioners . (2012). Accessed: February 22, 2020: https://www.fgdp.org.uk/guidance-standards/antimicrobial-prescribing-gdps .

10. Mainjot A, D'Hoore W, Vanheusden A, Van Nieuwenhuysen JP: Antibiotic prescribing in dental practice in Belgium. Int Endod J. 2009, 42:1112-1117. 10.1111/j.1365-2591.2009.01642.x

11. Tulip DE, Palmer NAO: A retrospective investigation of the clinical management of patients attending an out of hours' dental clinic in Merseyside under the new NHS dental contract. Br Dent J. 2008, 205:659-664. 10.1038/sj.bdj.2008.1044

12. Salako NO, Rotimi VO, Adib SM, Al-Mutawa S: Pattern of antibiotic prescription in the management of oral diseases among dentists in Kuwait. J Dent. 2004, 32:503-509. 10.1016/j.jdent.2004.04.001

13. Dailey YM, Martin MV: Are antibiotics being used appropriately for emergency dental treatment? . Br Dent J. 2001, 191:391-393. 10.1038/sj.bdj.4801190

14. Woolhouse M, Waugh C, Perry MR, Nair H: Global disease burden due to antibiotic resistance - state of the evidence. J Glob Health. 2016, 6:010306. 10.7189/jogh.06.010306

15. Handal T, Olsen I: Antimicrobial resistance with focus on oral beta-lactamases . Eur J Oral Sci. 2000, 108:163-174. 10.1034/j.1600-0722.2000.108003163.x

16. Sweeney LC, Dave J, Chambers PA, Heritage J: Antibiotic resistance in general dental practice-a cause for concern?. J Antimicrob Chemother. 2004, 53:567-576. 10.1093/jac/dkh137

17. Asmar G, Cochelard D, Mokhbat J, Lemdani M, Haddadi A, Ayoub F: Prophylactic and therapeutic antibiotic patterns of Lebanese dentists for the management of dentoalveolar abscesses. J Contemp Dent Pract. 2016, 17:425-433. 10.5005/jp-journals-10024-1867

18. Mansour H, Feghali M, Saleh N, Zeitouny M: Knowledge, practice and attitudes regarding antibiotics use among Lebanese dentists. Pharm Pract. 2018, 16:1272. 10.18549/PharmPract.2018.03.1272

19. American Association of Endodontists. Endodontic diagnosis. (2013). Accessed: February 22, 2020: https://www.aae.org/specialty/wp-content/uploads/sites/2/2017/07/endodonticdiagnosisfall2013.pdf.

20. Fair RJ, Tor Y: Antibiotics and bacterial resistance in the 21st Century . Perspect Medicin Chem. 2014, 6:2564. 10.4137/PMC.S14459

21. Teoh L, Stewart K, Marino R, Mccullough M: Antibiotic resistance and relevance to general dental practice in Australia. Aust Dent J. 2018, 63:414-421. 10.1111/adj.12643

22. WHO. Antimicrobial resistance. (2018). Accessed: February 22, 2020: https://www.who.int/news-room/factsheets/detail/antimicrobial-resistance.

23. Alyoussef AA: Clostridium difficile: epidemiology, pathogenicity, and an update on the limitations of and challenges in its diagnosis. J AOAC Int. 2018, 101:1119-1126. 10.5740/jaoacint.17-0352 